\title{
PREFERENSI LABEL DAN PERSEPSI KEMUDAHAN MEMPEROLEH PRODUK TERHADAP KEPUTUSAN PEMBELIAN SAYURAN ORGANIK
}

\section{LABEL PREFERENCE AND THE PERCEPTION OF THE EASE OF OBTAINING PRODUCTS FOR THE DECISION TO PURCHASE ORGANIC VEGETABLES}

\author{
Euis Dasipah*, Dety Sukmawati, Rahmah Sofiatin \\ Fakultas Pertanian Universitas Winaya Mukti \\ *Email: euisdasipah@gmail.com \\ (Diterima 01-07-2019; Diterima 22-07-2019)
}

\begin{abstract}
ABSTRAK
Penelitian ini bertujuan untuk mengetahui pengaruh preferensi label dan persepsi kemudahan memperoleh sayuran organik terhadap keputusan pembelian sayur organik. Sampel penelitian sebanyak 126 orang yang dipilih dengan menggunakan incidental sampling. Hasil penelitian menunjukkan bahwa secara simultan preferensi label dan persepsi kemudahan memperoleh produk berpengaruh positif dan signifikan terhadap keputusan pembelian dengan pengaruh total sebesar $43,2 \%$. Sedangkan secara parsial, preferensi label dan persepsi kemudahan memperoleh produk berpengaruh positif dan signifikan terhadap keputusan pembelian dengan pengaruh total masingmasing sebesar 19,6\% dan 23,6\%. Pengaruh langsung persepsi kemudahan memperoleh produk terhadap keputusan pembelian adalah sebesar 17\%. Hal ini berarti semakin mudah konsumen memperoleh sayuran organik maka keputusan konsumen untuk membeli produk sayuran organik semakin tinggi.
\end{abstract}

Kata kunci: Preferensi, Persepsi, Keputusan Pembelian, Sayur organik

\section{ABSTRACT}

This study aims to determine the effect of label preference and perception ease of obtaining organic vegetables on the decision to purchase organic vegetables. The research sample consisted of 126 people selected using incidental sampling. The results showed that simultaneous label preference and perception ease of obtaining products had a positive and significant effect on purchasing decisions with a total influence of $43.2 \%$. Whereas partially, label preference and perception ease of obtaining products have a positive and significant effect on purchasing decisions with a total influence of $19.6 \%$ and $23.6 \%$ respectively. The direct effect of the perception of the ease of obtaining a product on a purchasing decision is $17 \%$. This means that the more easily consumers get organic vegetables, the decision of consumers to buy organic vegetable products is higher.

Keywords: Preference, Perception, Purchasing Decisions, Organic Vegetables

\section{PENDAHULUAN}

Pelabelan organik merupakan jaminan atas keorganikan suatu produk organik. Pencantuman label organik tidak boleh dilakukan dengan sembarangan, tetapi harus memenuhi persyaratan tertentu, sehingga harus dilakukan secara legal dan spesifik.

Rendahnya konsumsi sayuran organik di Indonesia terkendala oleh persepsi dan preferensi konsumen tentang sayuran organik. Preferensi dam persepsi konsumen pada akhirnya dapat 


\section{PREFERENSI LABEL DAN PERSEPSI KEMUDAHAN MEMPEROLEH PRODUK \\ TERHADAP KEPUTUSAN PEMBELIAN SAYURAN ORGANIK \\ Euis Dasipah, Dety Sukmawati, Rahmah Sofiatin}

mempengaruhi keputusan konsumen dalam membeli sayuran organik.

Data hasil penelitian preferensi dan persepsi tersebut belum berlaku untuk semua daerah. Oleh karena itu, perlu dilakukan penelitian tentang preferensi dan persepsi yang berpengaruh tersebut, yaitu preferensi label dan persepsi kemudahan memperoleh sayuran organik di kota Bandung, untuk mengetahui apakah preferensi dan persepsi yang paling berpengaruh tersebut juga berlaku di kota Bandung.

Tujuan dari penelitian ini adalah untuk mengetahui dan menganalisis: (1) Pengaruh preferensi label terhadap keputusan pembelian, (2) Pengaruh persepsi kemudahan memperoleh sayuran organik terhadap keputusan pembelian, (3) Pengaruh preferensi label dan persepsi kemudahan memperoleh sayuran organik terhadap keputusan pembelian

\section{METODE PENELITIAN}

Pada penelitian ini sampel yang digunakan adalah metode non probability sampling dengan model sampling yaitu Incidental Sampling yaitu teknik penentuan sampel berdasarkan kebetulan, jadi siapa saja yang secara kebetulan/incidental bertemu dengan peneliti dapat digunakan sebagai sampel, bila dipandang orang yang kebetulan ditemui itu cocok sebagai sumber data.

Responden dalam penelitian ini adalah konsumen yang datang membeli sayuran organik di lokasi penyebaran kuesioner dan melakukan pembelian minimal satu kali dengan jumlah responden sebanyak 126 orang.

Jenis data primer yang diperoleh adalah melalui teknik pengumpulan data atas jawaban responden terhadap pertanyaan yang diberikan melalui kuesioner. Sebelum diterapkan, dilakukan uji instrumen terhadap kuesioner, yaitu:

1. Uji Validitas

Tujuan dilakukannya uji validitas adalah untuk menguji kevalidan kuesioner yang digunakan dalam penelitian.

2. Uji Reliabilitas

Uji reliabilitas dipakai untuk menilai kemampuan suatu hasil pengukuran relatif konsisten apabila pengukurannya diulangi dua kali atau lebih (Prayitno, 2010).

Analisis data yang digunakan dalam penelitian ini adalah sebagai berikut:

1. Analisis Deskriptif Statistik

Teknik analisis deskriptif digunakan untuk mendeskripsikan atau menggambarkan data yang telah 
terkumpul yang disusun secara runtut untuk generalisasi terhadap 126 responden yang meliputi: jenis kelamin, umur, pekerjaan, pendidikan dan pengetahuan responden tentang preferensi dan persepsi konsumen terhadap produk sayuran organik.

2. Analisis Kuantitatif

Analisis kuantitatif digunakan untuk mengetahui sejauh mana pengaruh preferensi label dan persepsi kemudahan memperoleh produk terhadap pengambilan keputusan pembelian sayuran organik.

a. Analisis Inferensial

Teknik analisis data yang digunakan untuk menentukan sejauh mana kesamaan antara hasil yang diperoleh dari suatu sampel dengan hasil akan didapat pada populasi secara keseluruhan. Jadi statistik inferensial membantu peneliti untuk mencari tahu apakah hasil yang diperoleh dari suatu sampel dapat digeneralisasi pada populasi

b. Analisis Faktor

Metode analisa faktor akan digunakan pada indikatorindikator pengukur variabel preferensi label, persepsi kemudahan produk, keputusan pembelian dan pemasaran.

c. Analisis Jalur (Path Analysis)

Pada penelitian ini peneliti dihadapkan pada model dimana variabel independen memberikan pengaruh terhadap variabel dependen, baik secara parsial maupun secara simultan, dan antar variabel independen terdapat korelasi.

\section{HASIL DAN PEMBAHASAN}

1. Uji Validitas dan Reliabilitas

Berdasarkan hasil uji validitas dan uji reliabilitas di bawah ini dapat disimpulkan bahwa item-item pertanyaan dalam kuesioner penelitian ini dapat dikategorikan sebagai valid dan reliabel.

\section{Analisis Deskriptif Statistik}

Mayoritas responden dalam penelitian ini adalah perempuan yang berada pada kisaran usia 25-45 tahun dan rata-rata berpendidikan $\mathrm{S} 1$ yang sebagian besar berprofesi sebagai pegawai swasta dimana mayoritas responden memberikan respon yang sangat tinggi terhadap preferensi label, persepsi kemudahan memperoleh produk dan respon yang 


\section{PREFERENSI LABEL DAN PERSEPSI KEMUDAHAN MEMPEROLEH PRODUK TERHADAP KEPUTUSAN PEMBELIAN SAYURAN ORGANIK \\ Euis Dasipah, Dety Sukmawati, Rahmah Sofiatin}

sangat tinggi terhadap keputusan

pembelian

\section{1) Analisis Inferensial Untuk Variabel Preferensi Label (X1)}

Deskripsi variabel preferensi label disajikan pada Tabel 1 .

\section{Analisis Kuantitatif}

\section{a. Analisis Inferensial}

Tabel 1. Deskripsi Variabel Preferensi Label (X1)

\begin{tabular}{|c|c|c|c|c|c|c|c|}
\hline \multirow{2}{*}{ INDIKATOR } & \multicolumn{5}{|c|}{ SKOR PILIHAN JAWABAN } & \multirow{2}{*}{$\begin{array}{l}\text { MEAN } \\
\text { ITEM }\end{array}$} & \multirow{2}{*}{$\begin{array}{c}\text { MEAN } \\
\text { INDIKATOR }\end{array}$} \\
\hline & SS & $\mathrm{S}$ & $\mathrm{KS}$ & TS & STS & & \\
\hline 1 & 0.49 & 0.37 & 0.08 & 0.03 & 0.03 & 3.25 & \\
\hline 2 & 0.47 & 0.39 & 0,09 & 0.01 & 0.03 & 3.25 & \\
\hline 3 & 0.50 & 0.33 & 0.10 & 0.03 & 0.02 & 3.36 & \\
\hline 4 & 0.25 & 0.48 & 0.17 & 0.04 & 0.04 & 3.08 & 3,24 \\
\hline 5 & 0.38 & 0.42 & 0.14 & 0.03 & 0.02 & 3.36 & \\
\hline 6 & 0.38 & 0.47 & 0.09 & 0.03 & 0.03 & 3.25 & \\
\hline 7 & 0.45 & 0.37 & 0.09 & 0.04 & 0.04 & 3.16 & \\
\hline
\end{tabular}

Tabel 1 menunjukkan bahwa

variabel preferensi label

berada dalam kategori

dipersepsikan kuat oleh

responden.

2) Analisis Inferensial Untuk

Variabel

\section{Persepsi}

Kemudahan Memperoleh

Produk (X2)

Deskripsi variabel

kemudahan memperoleh produk disajikan pada Tabel

2.

Tabel 2. Deskripsi Variabel Kemudahan Memperoleh Produk (X2)

\begin{tabular}{|c|c|c|c|c|c|c|c|}
\hline \multirow{2}{*}{ ITEM } & \multicolumn{5}{|c|}{ SKOR PILIHAN JAWABAN } & \multirow{2}{*}{$\begin{array}{c}\text { MEAN } \\
\text { ITEM }\end{array}$} & \multirow{2}{*}{$\begin{array}{c}\text { MEAN } \\
\text { INDIKATOR }\end{array}$} \\
\hline & SS & $\mathrm{S}$ & $\mathrm{KS}$ & TS & STS & & \\
\hline 1 & 0.26 & 0.50 & 0.18 & 0.03 & 0.02 & 3.36 & \\
\hline 2 & 0.30 & 0.37 & 0.24 & 0.06 & 0.02 & 3.36 & \\
\hline 3 & 0.33 & 0.50 & 0.11 & 0.04 & 0.02 & 3.36 & 3.18 \\
\hline 4 & 0.13 & 0.27 & 0.21 & 0.27 & 0.12 & 2.67 & \\
\hline 5 & 0.26 & 0.43 & 0.17 & 0.09 & 0.04 & 3.16 & \\
\hline
\end{tabular}

Tabel 2 menunjukkan bahwa

variabel persepsi kemudahan

memperoleh produk berada

dalam kategori dipersepsikan

kuat oleh responden.
3) Analisis Inferensial untuk Variabel Pembelian (Y)

Deskripsi variabel keputusan pembelian disajikan pada Tabel 3. 
MIMBAR AGRIBISNIS

Jurnal Pemikiran Masyarakat Ilmiah Berwawasan Agribisnis. Juli 2019. 5(2): 235-242

Tabel 3. Deskripsi Variabel Keputusan Pembelian (Y)

\begin{tabular}{cccccccc}
\hline \multirow{2}{*}{ INDIKATOR } & \multicolumn{5}{c}{ SKOR PILIHAN JAWABAN } & \multirow{2}{*}{$\begin{array}{c}\text { MEAN } \\
\text { ITEM }\end{array}$} & $\begin{array}{c}\text { MEAN } \\
\text { INDIKATOR }\end{array}$ \\
\cline { 2 - 5 } & SS & S & KS & TS & STS & & \\
\hline 1 & 0.31 & 0.47 & 0.17 & 0.03 & 0.02 & 3.36 & \\
2 & 0.19 & 0.48 & 0.25 & 0.04 & 0.03 & 3.25 & \multirow{2}{*}{3.19} \\
3 & 0.22 & 0.49 & 0.19 & 0.06 & 0.04 & 3.16 & \\
4 & 0.19 & 0.56 & 0.17 & 0.04 & 0.05 & 3.08 & \\
5 & 0.43 & 0.36 & 0.13 & 0.04 & 0.05 & 3.08 & \\
6 & 0.34 & 0.33 & 0.22 & 0.06 & 0.05 & 3.16 & \\
\hline
\end{tabular}
MEAN VARIABEL $=3.19$

Tabel 3 menunjukkan bahwa variabel keputusan pembelian berada dalam kategori dipersepsikan kuat oleh responden.

\section{b. Analisis Faktor}

1) Analisis Faktor Indikator Variabel Preferensi Label (X1)

Tabel 4. Nilai Loading Faktor Variabel Preferensi Label (X1)

\begin{tabular}{cc}
\hline Indikator & Loading Faktor \\
\hline X1.1 & 0,592 \\
X1.2 & 0,648 \\
X1.3 & 0,473 \\
X1.4 & 0,480 \\
X1.5 & 0,655 \\
X1.6 & 0,603 \\
X1.7 & 0,524 \\
\hline Sumber: Data Primer diolah, 2018
\end{tabular}

Pada Tabel 4 dapat dilihat bahwa indikator terkuat pengukur variabel preferensi label (X1) adalah adalah $\mathrm{X} 1.5$.

2) Analisis Faktor Indikator Variabel Persepsi Kemudahan Memperoleh Produk (X2)
Tabel 5. Nilai Loading Faktor Variabel Persepsi Kemudahan Memperoleh Produk (X2) Indikator Loading Faktor

\begin{tabular}{cc}
\hline Indikator & Loading Faktor \\
\hline X2.1 & 0,597 \\
X2.2 & 0,591 \\
X2.3 & 0,579 \\
X2.4 & 0,332 \\
X2.5 & 0,484 \\
\hline
\end{tabular}

Sumber: Data Primer diolah, 2018

Pada Tabel 5 dapat dilihat bahwa indikator terkuat pengukur variabel Persepsi Kemudahan Memperoleh Produk (X2) adalah X2.1.

\section{3) Analisis Faktor Indikator Variabel Keputusan Pembelian (Y)}

Tabel 6. Nilai Loading Faktor Variabel Keputusan Pembelian (Y)

\begin{tabular}{cc}
\hline Indikator & Loading Faktor \\
\hline Y1.1 & 0,619 \\
Y1.2 & 0,690 \\
Y1.3 & 0,690 \\
Y1.4 & 0,596 \\
Y1.5 & 0,767 \\
Y1.6 & 0,693 \\
\hline Sumber: Data Primer diolah, 2018
\end{tabular}

Pada Tabel 6 dapat dilihat bahwa indikator terkuat pengukur variabel keputusan pembelian (Y) adalah Y1.5. 


\section{PREFERENSI LABEL DAN PERSEPSI KEMUDAHAN MEMPEROLEH PRODUK \\ TERHADAP KEPUTUSAN PEMBELIAN SAYURAN ORGANIK \\ Euis Dasipah, Dety Sukmawati, Rahmah Sofiatin}

\section{c. Analisis Jalur (Path Analysis)}

\section{1) Uji Pengaruh Individual (Uji t)}

Tabel 7. Pengujian Individual

\begin{tabular}{cccccc}
\hline No. & Hipotesis & Koefisien Jalur $(\beta)$ & t hitung & t tabel & Kesimpulan \\
\hline 1. & $\rho \mathrm{yx}_{1} \neq 0$ & 0.360 & 4.726 & 1.348 & Ho ditolak \\
2. & $\rho \mathrm{vx}_{2} \neq 0$ & 0.412 & 5.409 & 1.348 & Ho ditolak
\end{tabular}

Tabel 7 menunjukkan bahwa berdasarkan hasil pengujian individual dengan membandingkan nilai t hitung dengan $t$ tabel diketahui bahwa kedua variabel yaitu preferensi label dan persepsi kemudahan memperoleh produk masing-masing berpengaruh signifikan terhadap keputusan pembelian (Y)

2) Uji Pengaruh Secara Simultan antara Variabel Preferensi Label (X1) dan Persepsi Kemudahan
Memperoleh Produk (X2) terhadap Variabel Keputusan Pembelian (Y)

Tabel 8. Pengujian Hipotesis Secara Simultan

\begin{tabular}{lll}
\hline Uji Pengaruh secara Uji F & Signifikansi
\end{tabular} simultan

$\begin{array}{lll}\text { X1 dan X2 } & 46,769 & 0,000\end{array}$

Tabel 8 menunjukkan bahwa dari hasil pengujian diketahui bahwa preferensi label dan persepsi kemudahan memperoleh produk berpengaruh terhadap pengambilan keputusan pembelian sayuran organik.

3) Analisis Pengaruh Total

Tabel 9. Pengaruh Langsung dan Pengaruh tidak langsung Hasil Analisis Jalur (Path Analysis)

\begin{tabular}{|c|c|c|c|c|c|c|c|c|}
\hline \multirow[t]{2}{*}{ Var } & \multirow{2}{*}{$\begin{array}{c}\text { Koefisien } \\
\beta\end{array}$} & \multicolumn{2}{|c|}{$\begin{array}{c}\text { Koefisien } \\
\text { Korelasi }\end{array}$} & \multirow[t]{2}{*}{$\begin{array}{l}\text { Pengaruh } \\
\text { langsung }\end{array}$} & \multicolumn{2}{|c|}{$\begin{array}{c}\text { Pengaruh Tidak } \\
\text { langsung }\end{array}$} & \multirow{2}{*}{$\begin{array}{l}\text { Total Pengaruh } \\
\text { Tidak Langsung }\end{array}$} & \multirow[t]{2}{*}{$\begin{array}{c}\text { total } \\
\text { pengaruh }\end{array}$} \\
\hline & & $\mathrm{X} 1$ & $\mathrm{X} 2$ & & $\mathrm{X} 1$ & $\mathrm{X} 2$ & & \\
\hline $\mathrm{X} 1$ & 0.360 & & 0.450 & 0.130 & & 0.067 & 0.067 & 0.196 \\
\hline $\mathrm{X} 2$ & 0.412 & 0.450 & & 0.170 & 0.067 & & 0.067 & 0.236 \\
\hline \multicolumn{8}{|c|}{ Total Pengaruh } & 0.432 \\
\hline
\end{tabular}

Tabel 9 menunjukkan bahwa berdasarkan uji pengaruh langsung dan tidak langsung analisis jalur (Analysis Path) terhadap preferensi label dan persepsi kemudahan memperoleh produk terhadap keputusan pembelian, diketahui bahwa pengaruh langsung lebih besar dibandingkan dengan pengaruh tidak langsung. Sehingga dengan demikian pengaruh tidak langsung dianggap tidak ada.

KESIMPULAN DAN SARAN 
Berdasarkan hasil analisis, maka dapat diambil kesimpulan sebagai berikut:

1. Preferensi label berpengaruh positif dan signifikan terhadap keputusan pembelian dengan pengaruh total sebesar 19,6\%. Pengaruh langsung preferensi label terhadap keputusan pembelian adalah sebesar $13 \%$ dan pengaruh tidak langsung sebesar $6,7 \%$. Hal ini berarti bahwa semakin tinggi keinginan dan kebutuhan konsumen akan label organik dapat terpenuhi maka keputusan konsumen untuk membeli produk organik semakin tinggi

2. Persepsi kemudahan memperoleh produk berpengaruh positif dan signifikan terhadap keputusan pembelian dengan pengaruh total sebesar 23,6\%. Pengaruh langsung persepsi kemudahan memperoleh produk terhadap keputusan pembelian adalah sebesar $17 \%$ dan pengaruh tidak langsung sebesar $6,7 \%$. Hal ini berarti semakin mudah konsumen memperoleh sayuran organik maka keputusan konsumen untuk membeli produk sayuran organik semakin tinggi

3. Preferensi label dan persepsi kemudahan memperoleh produk berpengaruh positif dan signifikan terhadap keputusan pembelian dengan pengaruh total sebesar $43,2 \%$. Hal ini berarti bahwa semakin tinggi preferensi label dan persepsi kemudahan memperoleh produk dapat dipenuhi maka akan semakin besar keputusan pembelian konsumen untuk membeli produk sayuran organik.

Berdasarkan hasil penelitian dan kesimpulan di atas, maka saran yang dapat dijadikan masukan adalah sebagai berikut:

1. Saran bagi Perusahaan Gerai Ritel sayuran organik dan produsen sayuran organik sebaiknya lebih memperhatikan label organik baik label tingkat maupun atribut labelnya sebagai bentuk jaminan "keorganikan" produk sayuran yang dijualnya untuk meningkatkan kepercayaan konsumen

2. Saran bagi Perusahaan Gerai Ritel sayuran organik dan produsen sayuran organik sebaiknya lebih memperhatikan kemudahan konsumen untuk memperoleh produk baik variasi jenis sayuran, stok, maupun penempatan sayuran organik di gerai ritel. 


\section{PREFERENSI LABEL DAN PERSEPSI KEMUDAHAN MEMPEROLEH PRODUK \\ TERHADAP KEPUTUSAN PEMBELIAN SAYURAN ORGANIK \\ Euis Dasipah, Dety Sukmawati, Rahmah Sofiatin}

3. Saran bagi peneliti selanjutnya dapat melakukan penelitian untuk atribut preferensi dan persepsi konsumen yang lainnya yang dapat berpengaruh terhadap keputusan pembelianm seperti jenis sayuran,manfaat, dan promosi sayuran organik

\section{DAFTAR PUSTAKA}

Prayitno. 2010. Layanan Bimbingan Kelompok dan Konseling Kelompok. Universitas Negeri Padang.

Pasolong, H. 2005. Metode Penelitian Administrasi: Untuk Organisasi
Profit dan Non Profit. Makasar. Lembaga Penerbitan Uhnas (Lephas).

Simamora, B. 2004. Panduan Riset Perilaku Konsumen. Jakarta: Gramedia Pustaka Utama.

Singarimbun, M. dan Effendi, S. 2002. Metode Penelitian Survey. Jakarta: LP3ES.

Suardika, M. Pasek, G. A. A Ambarawati, dan P. Sukaatmadja. 2014. Analisis Perilaku Konsumen Terhadap Keputusan Pembelian Sayur Organik CV Golden Leaf Farm Bali. Jurnal Manajemen Agribisnis 2(1): 1-10.

Sugiyono. 2011. Metode Penelitian Kuantitatif Kualitatif dan $R \& D$. Alfabeta. 